\title{
Diet optimization using linear programming to develop low cost cancer prevention food plan for selected adults in Kuala Lumpur, Malaysia
}

Reham Alaini ${ }^{1}$, Roslee Rajikan ${ }^{1 *}$ and Siti Masitah Elias ${ }^{2}$

\begin{abstract}
Background: Poor dietary habits have been identified as one of the cancer risks factors in various epidemiological studies. Consumption of healthy and balance diet is crucial to reduce cancer risk. Cancer prevention food plan should consist of all the right amounts of macronutrients and micronutrients. Although dietary habits could be changed, affordability of healthy foods has been a major concern, as the price of healthy foods are more expensive the unhealthy counterparts.

Methods: Therefore, using linear programming, this study is aimed to develop a healthy and balanced menu with minimal cost in accordance to individual needs that could in return help to prevent cancer. A cross sectional study involving 100 adults from a local university in Kuala Lumpur was conducted in 3 phases. The first phase is the data collection for the subjects, which includes their socio demographic, anthropometry and diet recall. The second phase was the creation of a balanced diet model at a minimum cost. The third and final phase was the finalization of the cancer prevention menu. Optimal and balanced menus were produced based on respective guidelines of WCRF/AICR (World Cancer Research Fund/ American Institute for Cancer Research) 2007, MDG (Malaysian Dietary Guidelines) 2010 and RNI (Recommended Nutrient Intake) 2017, with minimum cost.
\end{abstract}

Results: Based on the diet recall, most of subjects did not achieve the recommended micronutrient intake for fiber, calcium, potassium, iron, B12, folate, vitamin A, vitamin E, vitamin $\mathrm{K}$, and beta-carotene. While, the intake of sugar $(51 \pm 19.8 \mathrm{~g}),(13 \% \pm 2 \%)$ and sodium $(2585 \pm 544 \mathrm{~g})$ was more than recommended. From the optimization model, three menus, which met the dietary guidelines for cancer prevention by WCRF/AICR 2007, MDG 2010 and RNI 2017, with minimum cost of RM7.8, RM9.2 and RM9.7 per day were created.

Conclusion: Linear programming can be used to translate nutritional requirements based on selected Dietary Guidelines to achieve a healthy, well-balanced menu for cancer prevention at minimal cost. Furthermore, the models could help to shape consumer food choice decision to prevent cancer especially for those in low income group where high cost for health food has been the main deterrent for healthy eating.

Keywords: Balanced diet, Cancer prevention, Linear programming

\footnotetext{
* Correspondence: roslee@ukm.edu.my

'Dietetics Programme, Faculty of Health Sciences, Universiti Kebangsaan

Malaysia, 50300 Kuala Lumpur, Malaysia

Full list of author information is available at the end of the article
}

(c) The Author(s). 2019 Open Access This article is distributed under the terms of the Creative Commons Attribution 4.0 International License (http://creativecommons.org/licenses/by/4.0/), which permits unrestricted use, distribution, and reproduction in any medium, provided you give appropriate credit to the original author(s) and the source, provide a link to the Creative Commons license, and indicate if changes were made. The Creative Commons Public Domain Dedication waiver (http://creativecommons.org/publicdomain/zero/1.0/) applies to the data made available in this article, unless otherwise stated. 


\section{Background}

A balanced diet can be categorized with the concept of diversity and simplicity that is related with the perception of healthy eating [1]. Healthy diets are obtained by taking foods that contain recommended dose of macronutrients and micronutrients [2]. Dietary Guidelines can be adapted to promote health and preventing diet-related chronic diseases including cardiovascular disease, type 2 diabetes, some cancers, and obesity [3]. Throughout recorded history, wise choices of food and drink and of habitual behavior have been recommended to protect against cancer as well as other diseases, and to improve wellbeing. In Malaysia cancer is one of the major health problems [4]. It is undeniably one of the most important non-communicable diseases in Malaysia and contributed to $13.56 \%$ of all deaths occurred in the Ministry of Health Hospitals in 2015 [5]. Nutrition and related factors such as physical activity, obesity believed to contribute crucially to cancer occurrence [6].

Socioeconomic status of the population plays a critical role in eating patterns and food choices. Several studies have shown that energy-dense foods are foods that are commonly chosen by the low socioeconomic class due to their cheaper price [7] as financial resources are limited [8-11]. Foods of lower nutritional value and lower-quality diets generally cost less per calorie and tended to be selected by groups of lower socioeconomic status. A number of nutrient-dense foods were available at low cost but were not always palatable or culturally acceptable to the low-income consumer [12]. Furthermore, high price of healthy foods has been one of the main deterrents for healthy eating among the lower income group [13-15]. The encouragement toward healthy, balanced, affordable and palatable diet among the low-income group may improve their overall health status and eventually reduce the prevalence of chronic diseases in Malaysia including cancer.

Linear programming can be used to formulate minimum cost menus while making sure it met all the criteria of all macronutrients and micronutrients that has been set by dietary guidelines [16]. It is used in diet problem-solving techniques by creating a model that contains all the optimal food, cost and quality of a diet. By using linear programming, the majority of populations can benefit from an optimal diet at a minimum cost, which enables them to have an adequate daily nutrition within their financial potentials.

Linear programming has been applied in the Pacific Northwest of the USA, which was the only study that presents an application of mathematical optimization tools of dietary guidelines for cancer prevention. Six-specific food plans were generated that met both the key 2007 dietary recommendations for cancer prevention issued by the WCRF/AICR 2007 and the DRIs set by the Institute of Medicine [17].
Currently there is no study done in Malaysia to create a balanced, optimal diet for cancer prevention using linear programming at a minimum cost. Hence, this study aimed to construct a balanced, palatable and affordable diet that helps to prevent cancer at the lowest price possible to make it affordable and achievable for low income individuals.

\section{Methods}

This study was approved by the National University of Malaysia Medical Research Ethics Committee (UKMREC) (NN-2017-128). One hundred healthy adults aged 19 and above both male and female from a local university in Kuala Lumpur, staff and students, were randomly selected to participate in this study. Dietary intake and socio-demographic data were collected between September-October 2017.

\section{Data collection}

A set of questionnaires was distributed to the subjects to assess their socio-demographic profile. Basic information such as age, gender, marital status, and education level, lifestyle of the participants such as smoking habits, history of weight and height were obtained. Body mass index (BMI) was calculated by using weight and height and classified based on WHO BMI classification into underweight, normal, overweight and obesity in adults [18]. Eating pattern for both male and female staff and students of a local university in Kuala Lumpur, were recorded and assessed by three-day food records, where the subjects had to document their food intake for two days in a weekday and one over the weekend. Based on the subject's diet history information, a food list is prepared and the price for each food items was obtained from the Ministry of Domestic Trade, Cooperative, and Consumerism (KPDNKK). The food prices were set in terms of price per serving size.

\section{Statistical analysis}

Dietary intake was initially analyzed using Nutritionist $\mathrm{Pro}^{\mathrm{Tw}}$ software version 4.0.0 and compared with Recommended Nutrient Intake (RNI) 2017 for Malaysian [19]. The data was needed to calculate their energy intake and to assess eating pattern in order to plan a diet that emphasizes their preferences. Then both socio-demographic and dietary recall data were analyzed using statistical products and service solution (SPSS) program version 23.0. Descriptive analysis, which includes the mean, percentage and standard deviation, was used to find the average with its standard deviation. All the food items in the food list prepared were analyzed using Nutritionist Pro $^{\text {Tw }}$ software and market survey to determine the nutrient content i.e. energy, macronutrients 
and most micronutrients. Lastly, Excel Solver was utilized to produce the linear programming model.

Before running the program, the details of each macronutrient and micronutrient of food items, price per serving size, were filled in Microsoft Excel. The next step was setting up the constraints in the model such as upper bound (UL) and lower bound (LB) for energy, macronutrients and micronutrients. Excel Solver was later used to determine the optimal foods portion size that met all the dietary and nutrient recommendation of WCRF/AICR 2007 [20], MDG 2010 [21] and RNI 2017 [19] with the lowest possible cost. From the suggested foods portion, a daily balanced menu was later planned The optimization model will be repeated several times to produce two more suggested palatable menus with the lowest possible costs.

\section{Linear programming model development}

Cancer prevention diet models with the lowest cost were planned. The formulation for Linear Programming is as follows:

$$
\begin{aligned}
& \text { Minimize }: z=\sum c_{j} x_{j} \\
& \text { Subject to }: b_{i} \leq \sum a_{i j} x_{j} \leq b_{i} \text { and } x_{j} \geq 0
\end{aligned}
$$

The portion size of food item $j$ is represented as $x_{j} ; a_{i j}$ denotes the amount of nutrient $i$ in one portion of food item $j ; c_{j}$ was the cost of a portion of food item $j ; b_{i}$ denotes the largest or smallest acceptable quantity of nutrient $i$. The constraints in the model for this study were WCRF/AICR 2007 [20], MDG 2010 [21] and RNI 2017 [19]. Palatability constraints were also included to ensure that the suggested menus were suited to the subjects' common food pattern.

In this study, the cost of food items $(z)$ is the objective function that we want to minimize. Subjects' energy needs were calculated before the linear programming program started. The ideal energy of the subject was calculated using the Mifflin St-jeor Formula [22]. The minimum and maximum value of macronutrient and micronutrient were set based on WCRF/AICR 2007 [20], MDG 2010 [21] and RNI 2017 [19]. Choosing food items from the dietary recall of the subjects and avoiding the repetition or large portions of certain foods were also considered to ensure the palatability of the menu.

\section{Results}

\section{Socio-demographic data}

A total of 100 subjects from staff and students of participated in this study, with the females constitute the majority $(65 \%)$ and the remaining balance of $35 \%$ was male. The mean age of female subjects was $24 \pm 5.5$ years, where more than $50 \%$ of female were between the ages 19 to 29 years. While, the mean age for male subjects was $25 \pm 6$ years, where more than $59 \%$ were between 19 to 29 years old. More than two-third (79\%) was single and the rest (21\%) were married. Based on the results, all of the subjects completed at least secondary schooling while $20 \%$ have completed a bachelor's degree or higher.

\section{Anthropometric measurements}

Anthropometric measurements were taken from the subjects. After the weight and height of the subjects were obtained, Body Mass Index (BMI) was calculated for each subject. Majority of the study population (48\%) had normal BMIs between $18.5 \mathrm{~kg} / \mathrm{m}^{2}$ and $24.9 \mathrm{~kg} / \mathrm{m}^{2}$, which were almost similar to the prevalence of normal body weight of healthy Malaysian adults of $45.6 \%$ (National Health Morbidity Survey 2015) [23]. On the other hand, $33 \%$ of the subjects had BMIs between $25 \mathrm{~kg} / \mathrm{m}^{2}$ and $29.9 \mathrm{~kg} / \mathrm{m}^{2}$, thus belonging to the overweight classification. Prevalence of overweight for healthy Malaysian adults was $30 \%$, which is almost similar to the subjects (National Health Morbidity Survey 2015) [23]. The remaining $19 \%$ were classified as obese.

\section{Dietary intake}

All the macronutrients average intake of the subjects was met as shown in Table 1. Similarly, according to MANS 2008, the proportions of calories derived from macronutrients were within the recommendations for a healthy diet, while intake of micronutrients such as iron, calcium and vitamin A was about $50 \%$ of RNI particularly in women [24].

Fiber intake was only $7.5 \pm 4.05 \mathrm{~g}$, thus failing to meet the prescribed recommendations (Table 1). Only $30 \%$ of the subjects meet the recommendations for fiber. The average intake of non-starchy vegetables and fruits were below the recommended amount of WCRF/AICR 2007 ( 2.4 versus 5 serving per day). In addition, the average intake of unprocessed grains and legumes were also below the recommendation (0.7 versus 3 serving). Malaysian Adult Nutrition Survey (MANS) 2014 [25] revealed that Malaysian adults on average do not consume sufficient fruits and vegetable in terms of frequency and amount, therefore does not achieve the recommended intake of fibers and other micronutrients. In this study, no subject met the requirement for iron and folic acid. Other micronutrients intakes such as calcium, vitamin B3, B12, vitamin $\mathrm{C}$, vitamin $\mathrm{E}$, vitamins $\mathrm{K}$ were also poor. Similarly, the MANS 2014 [25] also reported that the intake of micronutrients in relation to RNI could be described as low particularly for calcium and vitamin $C$ intake. Healthy Eating Index for Malaysians showed that only a small percentage of Malaysian met dietary requirements and found that majority of the respondents $(80.7 \%)$ were at risk of poor diet quality [26]. As for zinc, selenium and phosphorous, all subjects achieved the 
Table 1 The average energy/macronutrients/micronutrients intake with the recommendations and percentage of subjects achieving recommendations

\begin{tabular}{|c|c|c|c|c|}
\hline $\begin{array}{l}\text { Energy/Macronutrient / } \\
\text { Micronutrient }\end{array}$ & $\begin{array}{l}\text { Average Intake } \pm \\
\text { SP }\end{array}$ & $\begin{array}{l}\text { Percentage of Intake from } \\
\text { Energy }\end{array}$ & Recommendation & $\begin{array}{l}\% \text { Of subjects achieving } \\
\text { Recommendation }\end{array}$ \\
\hline Energy (kcal) & $1580 \pm 300$ & & & 70.5 \\
\hline Protein (g) & $56 \pm 18.5$ & $14.7 \% \pm 4.6 \%$ & $10-20 \%^{3}$ & 78 \\
\hline Carbohydrates (g) & $203 \pm 45.8$ & $53.5 \% \pm 11.2 \%$ & $50-65 \%^{3}$ & 66 \\
\hline Fat (g) & $48 \pm 17.09$ & $28.5 \% \pm 9.5$ & $25-30 \%^{3}$ & 59 \\
\hline Cholesterol (mg) & $184 \pm 91$ & - & $<300 \mathrm{mg} /$ day $^{3}$ & 89 \\
\hline Saturated Fat (g) & $15 \pm 6.8$ & $9 \% \pm 1 \%$ & $<10 \%{ }^{1}$ & 79 \\
\hline Monounsaturated (g) & $11 \pm 5$ & $6.5 \% \pm 2.5 \%$ & $12-15 \%^{3}$ & 2 \\
\hline Polyunsaturated (g) & $9 \pm 4$ & $5.3 \% \pm 2.5 \%$ & $3-7 \%^{3}$ & 33 \\
\hline Fibre (g) & $7.5 \pm 4$ & - & $25-30^{1}$ & 0 \\
\hline Sodium (mg) & $2585 \pm 544$ & - & $<2000^{1}$ & 20 \\
\hline Potassium & $1181 \pm 483$ & - & $\geq 4700^{3}$ & 0 \\
\hline Vitamin A & $954 \pm 812$ & - & $600-3000^{3}$ & 80 \\
\hline Beta-Carotene & $1061 \pm 813$ & - & $2500^{1}$ & 6 \\
\hline Vitamin E (mg) & $4 \pm 2.3$ & - & $7.5-1000^{3}$ & 10 \\
\hline Vitamin K $(\mu \mathrm{g})$ & $32 \pm 20$ & - & $55-1000^{3}$ & 15 \\
\hline Vitamin C (mg) & $36 \pm 25$ & - & $70-2000^{3}$ & 8 \\
\hline Vitamin B12 $(\mu \mathrm{g})$ & $2 \pm 1.5$ & - & $\geq 4^{3}$ & 20 \\
\hline Folate $(\mu \mathrm{g})$ & $124 \pm 76.6$ & - & $400-1000^{3}$ & 2 \\
\hline Iron (mg) & $13 \pm 5.2$ & - & $29-45^{3}$ & 0 \\
\hline Calcium & $418 \pm 226$ & - & $1000-2500^{3}$ & 0 \\
\hline Thiamine (mg) & $1 \pm 0.2$ & - & $\geq 1.1^{3}$ & 33 \\
\hline Riboflavin (mg) & $1 \pm 0.9$ & - & $\geq 1.1^{3}$ & 45 \\
\hline Niacin (mg) & $11 \pm 4$ & - & $14-35^{3}$ & 26 \\
\hline Zinc (mg) & $5.5 \pm 1.61$ & - & $4.7-35^{3}$ & 30 \\
\hline Magnesium (mg) & $124 \pm 70.8$ & - & $320-500^{3}$ & 0 \\
\hline Copper (mg) & $0.6 \pm 0.5$ & - & $0.9-2^{3}$ & 10 \\
\hline Selenium $(\mu \mathrm{g})$ & $35 \pm 18.4$ & - & $24-400^{3}$ & 66 \\
\hline Phosphorus (mg) & $822 \pm 322$ & - & $700-3000^{3}$ & 67 \\
\hline Sugar (g) & $51 \pm 19.8$ & - & $<10^{3}(50 \mathrm{~g})$ & 44 \\
\hline
\end{tabular}

Source: 'WCRF/AICR 2007, ${ }^{2}$ MDG 2010, ${ }^{3}$ RNI 2017

recommended requirements set by the RNI 2017. While for potassium, the average intake of a subject was $1181 \pm 480 \mathrm{mg}$, and none of the subjects met the recommendation requirement of the RNI 2017, which is 4700 $\mathrm{mg}$. The average intake for sugar and sodium were (51 \pm $19.8 \mathrm{~g})$ and $(2585 \pm 544 \mathrm{~g})$ respectively, which exceeds the recommendations.

The average intake of red and processed meat is less than $300 \mathrm{~g}$ per week, meeting the recommendations of WCRF/ AICRF 2007. However, the intake of processed food and salt was higher than the recommended amount. Likewise, MANS 2014 [25] showed that consumption of "processed foods" added with salt and condiments had increased and appeared among the top ten most consumed foods by
Malaysian adults. Red meat consumption is associated with the formation of N-nitroso compounds. This increases the level of nitrogenous residues in the colon and is associated with the formation of DNA adducts in colon cells. High intake of red meat may result in more absorption of haem iron, greater oxidative stress and potential for DNA damage. Beside, red meat is high in animal fat and is energy dense food. All these factors contribute for considering red and processed meat as a cause of colorectal cancer [27].

\section{Development of cancer prevention model and menu with minimum cost}

Linear programming has been used to formulate nutritionally optimal dietary patterns, to examine the 
Table 2 Comparison of the three models produced with WCRF/AICR, MDG, RNI and palatability constrains

\begin{tabular}{|c|c|c|c|c|c|}
\hline Constrain & LB & UB & Model I & Model II & Model III \\
\hline \multicolumn{6}{|l|}{ WCRF/AICR 2007} \\
\hline Non-Starchy Vegetables and fruits (serving/day) & 5 & - & 13 & 14.5 & 11.5 \\
\hline Cooked Vegetables & - & - & 6 & 3.5 & 6 \\
\hline Salad & - & - & 1 & 2 & - \\
\hline Spices & - & - & 4 & 6 & 3.5 \\
\hline Fruits & - & - & 2 & 3 & 2 \\
\hline Red and Processed meat (serving/week) & - & 3.5 & 0 & 0 & 0 \\
\hline Unprocessed grains and legumes (serving/day) & 1 & - & 2 & 2 & 5 \\
\hline Fibre (g) & 25 & 35 & 32.3 & 26 & 26.3 \\
\hline Sodium (g) & 500 & 2000 & 563 & 1631 & 1853 \\
\hline \multicolumn{6}{|l|}{ MDG 2010} \\
\hline Cereals and Grains (serving) & 6 & 8 & 6.5 & 6 & 6 \\
\hline Meat/Poultry (serving) & 1 & 2 & 1 & 1 & 2 \\
\hline Fish (serving) & 1 & 3 & 1 & 1 & 2.5 \\
\hline Legumes (serving) & 0.5 & 1 & 1.5 & 1 & 1 \\
\hline \multicolumn{6}{|l|}{ Palatability } \\
\hline Vegetable oil (serving) & 1 & 2 & & 1 & \\
\hline Palm Oil (serving) & 1 & 2 & & 2 & 2 \\
\hline \multicolumn{6}{|l|}{ RNI 2017} \\
\hline Energy (kcal) & 1600 & 2000 & 1802 & 1685 & 1889 \\
\hline Protein (g) & 42 & 100 & 69.5 & 58 & 102 \\
\hline Carbohydrates (g) & 212 & 300 & 224 & 218 & 236 \\
\hline Fat (g) & 38 & 68 & 62 & 59 & 56 \\
\hline Cholesterol (mg) & 60 & 200 & 135.7 & 116 & 217 \\
\hline Saturated Fat (g) & 10 & 22 & 16.5 & 10.5 & 19.9 \\
\hline Monounsaturated (g) & 22 & 33 & 23 & 19.8 & 23.6 \\
\hline Polyunsaturated (g) & 10 & 15 & 15 & 13.7 & 13.5 \\
\hline Potassium (mg) & 4700 & 10,000 & 4729 & 4696 & 4704 \\
\hline Vitamin A (RE) & 600 & 3000 & 4826 & 1913 & 1409 \\
\hline Beta-Carotene & 2500 & 17,000 & 10,430 & 10,516 & 6365 \\
\hline Vitamin E (mg) & 7.5 & 1000 & 12 & 10.2 & 13.2 \\
\hline Vitamin $\mathrm{K}(\mu \mathrm{g})$ & 55 & 1000 & 55 & 71.6 & 99.7 \\
\hline Vitamin C (mg) & 70 & 1000 & 549 & 233 & 274 \\
\hline Vitamin B12 $(\mu \mathrm{g})$ & 4 & 23 & 11.5 & 7.3 & 6.6 \\
\hline Folate $(\mu \mathrm{g})$ & 400 & 1000 & 413 & 450 & 475 \\
\hline Calcium (mg) & 1000 & 2500 & 1000 & 1143 & 1113 \\
\hline Iron (mg) & 29 & 45 & 29.5 & 30 & 29 \\
\hline Thiamine (mg) & 1.1 & 500 & 10 & 2.2 & 1.8 \\
\hline Riboflavin (mg) & 1.1 & 25 & 3.4 & 2.3 & 3.2 \\
\hline Niacin (mg) & 14 & 35 & 32 & 29 & 28.5 \\
\hline Zinc (mg) & 4.7 & 35 & 6.1 & 10.6 & 17.7 \\
\hline Magnesium (mg) & 320 & 500 & 227 & 342 & 298 \\
\hline Copper (mg) & 0.9 & 2 & 1.4 & 1.1 & 1.5 \\
\hline Selenium $(\mu \mathrm{g})$ & 24 & 400 & 47 & 43 & 23 \\
\hline
\end{tabular}


Table 2 Comparison of the three models produced with WCRF/AICR, MDG, RNI and palatability constrains (Continued)

\begin{tabular}{llllll}
\hline Constrain & LB & UB & Model I & Model II & Model III \\
\hline Phosphorus (mg) & 700 & 4000 & 1370 & 1507 & 1608 \\
Sugar (g) & 0 & 50 & 47 & 48 & 45 \\
\hline
\end{tabular}

relationship between diet cost and diet quality in Western countries and to develop food-based dietary guidelines in developing countries where residents need to achieve nutritional requirement with their limited income of diet [28]. Similarly, a Malaysian study done by Rajikan et al. developed a healthy and palatable diet for low income women at the minimum cost based on Malaysian Dietary Guidelines 2010 and Recommended Nutrient Intake 2005 via linear programming [29]. Optimization models provide an elegant mathematical solution that can help to determine that a set of dietary guidelines is achieved by Malaysian population subgroups. There were three models produced by linear programming. Table 2 shows all nutrients constrains and the food groups of the three different models produced by LP based on the dietary guidelines of WCRF/AICR 2007, MDG 2010 and RNI 2017. The three models produced, fulfilled the upper and the lower limits of the constrains including macronutrient and micronutrient recommendations set by WCRF/AICR 2007 and RNI 2017, the serving size of the food groups based on WCRF/AICR 2007 and MDG 2010. The palatability factor was also considered by including servings from vegetable oil and palm oil.

Looking at the three LP models as shown in Table 2, iron, potassium and calcium only reached the lower limit of the constraint values. However, other nutrients such as carbohydrate $(\mathrm{CHO})$, fat, vitamin $\mathrm{A}$ and fiber reached the upper limit of the maximum acceptable value of constraints.

The food list selected comprised mainly on fruits and vegetables with the highest serving, as complex mixture of phytochemicals present in whole vegetables and fruits may have additive and synergistic effects responsible for anti-cancer activities [6]. Beside, these food items are low-energy density and high in fibers, which will provide sufficient fibers to meet the recommendations of $25-\mathrm{g}$ fibers by WCRF/AICR and meeting the new recommendation of RNI 2017 for potassium.

From the suggested food list of the models, it is understood that each model consisted of at least two servings of whole and unprocessed grains such as brown rice, oat, lentils, and whole meal bread, thus ensuring high fiber and nutrient contents. The food list for each model also provides at least two servings of fruits and more than nine servings of vegetables, although it resulted in slight variation of the existing diets. In consequence, an optimal cancer prevention menu is developed based on a model that was produced using a linear programming method where it meets the requirements of constraints based on the dietary guidelines of WCRF/AICR 2007, MDG 2010, and RNI 2017.

Table 3 Developments of three cancer prevention menus with minimal cost

\begin{tabular}{|c|c|c|c|}
\hline Meal & Menu 1 & Menu 2 & Menu 3 \\
\hline Breakfast & $\begin{array}{l}\text { Fried Kuey Teow } \\
\text { (1 cup) } \\
\text { Papaya (1 slice) }\end{array}$ & $\begin{array}{l}\text { Laksa Penang with sardine (1 1/2 } \\
\text { cup) } \\
\text { Pineapple ( } 1 \text { cup) }\end{array}$ & $\begin{array}{l}\text { Hailam Noodle with chicken (1 cup) } \\
\text { Banana (1 piece) }\end{array}$ \\
\hline Morning snack & $\begin{array}{l}\text { Bubur Kacang Hijau dan } \\
\text { Keledek with sweet potatoes (1 1/2 cup) }\end{array}$ & $\begin{array}{l}\text { Oat cookies } \\
\text { ( } 2 \text { pieces) }\end{array}$ & $\begin{array}{l}\text { Cream Crackers } \\
\text { ( } 3 \text { pieces) } \\
\text { Coffee plain (1 cup) }\end{array}$ \\
\hline Lunch & $\begin{array}{l}\text { Steamed Brown Rice (3scoops) } \\
\text { Fried Indian Mackerel ( } 1 \text { medium piece) } \\
\text { Spinach Soup with tomato (1cup) }\end{array}$ & $\begin{array}{l}\text { Steamed Basmati Rice ( } 3 \text { scoops) } \\
\text { Soy Sauce Chicken ( } 1 \text { medium } \\
\text { piece) } \\
\text { Ulam Raja ( } 1 \text { cup) } \\
\text { Steamed cabbage } \\
\text { (1 cup) }\end{array}$ & $\begin{array}{l}\text { Basmati Rice (3scoops) } \\
\text { Grilled Catfish + Air Asam (medium piece) } \\
\text { Sambal Lady Finger ( } 1 \text { cup) }\end{array}$ \\
\hline Afternoon snack & $\begin{array}{l}\text { Capati ( } 1 \text { piece) } \\
\text { Dhal Gravy with turmeric and carrots ( } 1 \text { 1 } 1 / 2 \\
\text { cup) }\end{array}$ & $\begin{array}{l}\text { Banana Oat Smoothie with milk } \\
\text { (1 cup) }\end{array}$ & $\begin{array}{l}\text { Peanut Butter Sandwich (1 sandwich) } \\
\text { Chocolate Drink ( } 1 \text { cup) }\end{array}$ \\
\hline Dinner & $\begin{array}{l}\text { Steamed Brown Rice ( } 3 \text { scoops) } \\
\text { Grilled Chicken Breast ( } 2 \text { pieces) } \\
\text { Fried Pucuk Paku } \\
\text { (1 cup) } \\
\text { Guava (1 piece) }\end{array}$ & $\begin{array}{l}\text { Fried Rice with sardine (3 scoops) } \\
\text { Ulam Raja ( } 1 \text { cup) } \\
\text { Stir fried Red spinach } \\
\text { Orange/carrot juice } \\
\text { (1 cup) }\end{array}$ & $\begin{array}{l}\text { Basmati rice ( } 3 \text { scoops) } \\
\text { Masak Lemak with tempeh and vegetables ( } 1 \\
\text { cup) } \\
\text { Mango ( } 1 \text { piece) }\end{array}$ \\
\hline $\begin{array}{l}\text { Food Cost per day } \\
\text { (RM) }\end{array}$ & RM 7.8 & RM 9.2 & RM 9.7 \\
\hline
\end{tabular}


Table 3 shows the three menus produced, according to raw food items at the lowest possible cost based on WCRF/AICR, MDG, RNI and palatability constraints by using LP. The production of every menu is different from another as it follows the list of food ingredients selected according to the LP models. For each model, every list of ingredients included in the model will have a slight difference by removing food items that have been selected in the previous menus or placing limits on the same food from a model to the next model so that quantities are different or not selected by the next model. Therefore, the price is expected to increase from menu 1 to menu 3 as the models have stricter requirement and the cheapest nutritionally dense foods have been chosen in the previous model. The development of these menus had different energy levels within the lower and the upper limit set for kcal (1600-2000 kcal). Model 1 is $1802 \mathrm{kcal}$ with the lowest price RM 7.8 (USD 1.97), model 2 is 1680 with RM9.2 (USD 2.35) and model 3 is $1889 \mathrm{Kcal}$ with the highest price RM 9.7(USD 2.48).

\section{Discussion}

Diets that give more emphasis to those plant foods that are high in nutrients, high in dietary fiber, and low in energy density, (non- starchy vegetables \& fruits) probably protect against some cancers such as: mouth, pharynx, esophagus, stomach colorectal, lung, pancreas and prostate [20]. These foods are high in antioxidants (carotenoids, beta-carotene, lycopene and Allium) such as, pink sweet potatoes, papaya, tomato, onions, garlic, mango, carrots and fiber, which are low in energy density, and so, promote healthy weight.

In addition, we can observe that the menu also emphasizes on the intake of cruciferous vegetables, such as broccoli, mustard leaves, cabbage and cauliflower which are associated with the reduction in the risk of several types of cancer [30]. The traditional food tempeh, which is rich in phytoestrogens, is also included in the menu as seen in menu 3, as it is found to exhibit a plethora of different anti-cancer effects, including inhibiting proliferation [31]. Developing cancer prevention diet requires little modification from the existing diet mainly by increasing the vegetables and fruit serving.

The recommended menu used only a dash of salt in seasoning the dishes and this causes the resulting menu to have a low sodium amount of less than $2000 \mathrm{mg}$. Studies showed that salt and salt-preserved foods are probably a cause of stomach cancer [32]. The other alternatives are to use natural flavoring to replace salt are turmeric, onions, garlic, chili and mustard leaves that contain lower sodium content.

The menu also restricted the use of added sugar and the intake of sugary drinks, except for sugar that is naturally found in fruits and vegetables. Instead, healthy high antioxidant drinks were suggested such as carrot and orange juice. Furthermore, it is evident that the diet models do not include any processed meat, fast food, or sugary drinks; where lean proteins were the only protein source.

Looking at the fat content in the three models, we can see that it emphasizes on less saturated fats and trans-fat by reducing the consumption of fat, which is mainly achieved by appropriate cooking methods. Based on the menu that has been set up, almost all models use a minimal of 3 tablespoons of oil. Therefore, the menu is provided with many ways of cooking such as steaming, baking or grilling. In a study conducted by Asmaa et al. [33], the use of healthy cooking methods such as steaming can reduce fat content in food.

However, there were few limitations in this study. The subjects in this study may have not been representative because they were not randomly sampled from the general Malaysian population, rather, they were only limited to a local university staff and students. A larger number of subjects were from different economic and social background and thus more lists of food items should be included in the model to increase the variety of food choices in future studies.

\section{Conclusion}

In general, the use of linear programming is a very effective tool in producing a balanced diet and can easily interpret dietary recommendations into a nutritional model that is based on local market prices. It formulated the current guidelines for cancer prevention by creating a balanced and optimal diet for cancer prevention at minimum cost with more specific details and accuracy. In addition, because this research focuses on the specific nutrients needed at minimal cost, the menus produced are ideal for people who want to maintain healthy eating habits but experience financial difficulties.

\section{Abbreviations \\ AICR: American Institute for Cancer Research; BMl: Body Mass Index; DNA: Deoxyribonucleic Acid; DRI: Dietary Recommended Intake; KPDNKK: Ministry of Domestic Trade, Cooperative, and Consumerism; LB: Lower bound; LP: Linear Programming; MANS: Malaysian Adult Nutrition Survey; MDG: Malaysian Dietary Guidelines; NHMS: National Health Morbidity Survey; RNI: Recommended Nutrient Intake; UKMREC: Universiti Kebangsaan Malaysia (National University of Malaysia) Medical Research Ethics Committee; UL: Upper bound; WCRF: World Cancer Research Fund}

\section{Acknowledgments}

The authors would like to thank all of the subjects for their cooperation and support toward this research project.

\section{Funding}

The authors acknowledged the financial assistance for publication received from the Research University Grant awarded by the Ministry of Health to the National University of Malaysia specifically for the Consortium of B40 Research (CB40R) under the auspice of B40 Grand Challenges (IDE 2018-01). 


\section{Availability of data and materials}

The datasets used and/or analyzed during the current study are not publicly available due to limited consent of the study participants but are available from the corresponding author on reasonable request.

\section{About this supplement}

This article has been published as part of BMC Public Health Volume 19 Supplement 4, 2019: Health and Nutritional Issues Among Low Income Population in Malaysia. The full contents of the supplement are available online at https://bmcpublichealth.biomedcentral.com/articles/supplements/ volume-19-supplement-4.

\section{Authors' contributions}

RR and SME conceived of the presented idea. RA did the data collection, performed the computations, analysed the data and drafted the manuscript. RA and SME verified the analytical methods and supervised the findings of this work. All authors provided critical feedback and helped shape the research, analysis and manuscript. All authors have read and approved the manuscript.

\section{Ethics approval and consent to participate}

This study was approved by the Universiti Kebangsaan Malaysia (National University of Malaysia) Medical Research Ethics Committee (UKMREC) (NN2017-128). All participants provided written consent.

\section{Consent for publication}

Not applicable

\section{Competing interests}

The authors declare that they have no competing interests.

\section{Publisher's Note}

Springer Nature remains neutral with regard to jurisdictional claims in published maps and institutional affiliations.

\section{Author details}

${ }^{1}$ Dietetics Programme, Faculty of Health Sciences, Universiti Kebangsaan Malaysia, 50300 Kuala Lumpur, Malaysia. ${ }^{2}$ Financial Mathematics Programme, Faculty of Science and Technology, Universiti Sains Islam Malaysia, 71800 Nilai, Negeri Sembilan, Malaysia.

\section{Published: 13 June 2019}

\section{References}

1. Falk LW, Sobal J, Bisogni CA, Connors M, Devine CM. Managing healthy eating: definitions, classifications, and strategies. Health Educ Behav. 2001; 28(4):425-39.

2. Maillot M, Drewnowski A, Vieux F, Darmon N. Quantifying the contribution of foods with unfavourable nutrient profiles to nutritionally adequate diets. Br J Nutr. 2011;105(8):1133-7.

3. DeSalvo KB, Olson R, Casavale KO. Dietary guidelines for Americans. JAMA. 2016;315(5):457-8.

4. Ahmad N, Jaafar MS, Bakhash M, Rahim M. An overview on measurements of natural radioactivity in Malaysia. J Radiat Res Appl Sci. 2015;8(1):136-41.

5. Azizah A, Nor Saleha I, Noor Hashimah A, Asmah Z, Mastulu W. Malaysian National Cancer Registry Report 2007-2011: Malaysia Cancer statistic, data and figure. Malaysia: National Cancer Institute; 2016.

6. Ghazi HF, Hasan TN, Isa ZM, AbdalQader MA, Abdul-Majeed S. Nutrition and breast cancer risk: review of recent studies. Malaysian J Pub Health Med. 2016;16(1):75-80

7. Cuco G, Arija V, Marti-Henneberg C, Fernandez-Ballart J. Food and nutritional profile of high energy density consumers in an adult Mediterranean population. Eur J Clin Nutr. 2001;55(3):192.

8. Dachner N, Ricciuto L, Kirkpatrick SI, Tarasuk V. Food purchasing and food insecurity: among low-income families in Toronto. Can J Diet Pract Res. 2010;71(3):e50-6.

9. Darmon N, Briend A, Drewnowski A. Energy-dense diets are associated with lower diet costs: a community study of French adults. Public Health Nutr. $2004 ; 7(1): 21-7$
10. Drewnowski A, Darmon N, Briend A. Replacing fats and sweets with vegetables and fruits-a question of cost. Am J Public Health. 2004;94(9): 1555-9.

11. Dowler E. Budgeting for food on a low income in the UK: the case of loneparent families. Food Policy. 1997;22(5):405-17.

12. Darmon N, Drewnowski A. Contribution of food prices and diet cost to socioeconomic disparities in diet quality and health: a systematic review and analysis. Nutr Res. 2015;73(10):643-60.

13. de Mestral C, Stringhini S, Marques-Vidal P. Barriers to healthy eating in Switzerland: a nationwide study. Clin Nutr. 2016;35(6):1490-8.

14. Lennernäs M, Fjellström C, Becker W, Giachetti I, Schmitt A, De Winter A, Kearney M. Influences on food choice perceived to be important by nationally-representative samples of adults in the European Union. Eur J Clin Nutr. 1997:51.

15. Glanz K, Basil M, Maibach E, Goldberg J, Snyder D. Why Americans eat what they do: taste, nutrition, cost, convenience, and weight control concerns as influences on food consumption. J Am Diet Assoc. 1998;98(10):1118-26.

16. Pasic M, Catovic A, Bijelonja I, Crnovrsanin S. Linear programming local cost nutrition optimization model: Annals of DAAAM \& Proceedings; 2011. p. 0389-90. muw. daaam.info/Downloads/pdf/proceedings/proceedings_2011/0389_Pasic.pdf.

17. Masset G, Monsivais P, Maillot M, Darmon N, Drewnowski A. Diet optimization methods can help translate dietary guidelines into a cancer prevention food plan. J Nutr. 2009;139(8):1541-8.

18. WHO EC. Appropriate body-mass index for Asian populations and its implications for policy and intervention strategies. Lancet (London, England). 2004:363(9403):157.

19. National Coordinating Committee on Food and Nutrition (NCCFN). Recommended nutrient intakes for Malaysia: Ministry of Health Malaysia; 2017.

20. World Cancer Research Fund / American Institute for Cancer Research. Food, nutrition, physical activity, and the prevention of Cancer: a global perspective. Washington DC: AICR; 2007.

21. National Coordinating Committee on Food and Nutrition (NCCFN). Malaysian dietary guidelines 2010: Ministry of Health Malaysia; 2010. dg. sncoc.org/upload/affix/20140818104029708.pdf.

22. Rao ZY, Wu XT, Liang BM, Wang MY, Hu W. Comparison of five equations for estimating resting energy expenditure in Chinese young, normal weight healthy adults. Eur J Pharm Med. 2012;17(1):26.

23. Institute for Public Health. National health and morbidity survey 2015. Noncommunicable diseases, risk factors \& other health problems. Vol. II. Institute for Public Health Report No. NMRR-14-1064-21877. 2015.

24. Mirnalini JK, Zalilah M, Safiah M, Tahir A, Siti MH, Siti DR, et al. Energy and nutrient intakes: findings from the Malaysian adult nutrition survey (MANS). Malays J Nutr. 2008;14(1):1-24.

25. Institute for Public Health. National health and morbidity survey 2014. Malaysian adult nurition survey. Vol. I. Institute for Public Health Report No. NMRR-12-815-13100. 2014. iku.moh.gov.my.

26. Rezali FW, Chin YS, Mohd Shariff Z, Yusof M, Nisak B, Sanker K, Woon FC. Evaluation of diet quality and its associated factors among adolescents in Kuala Lumpur, Malaysia. Nutr Res Pract. 2015;9(5):511-6.

27. Hughes LA, Simons CC, van den Brandt PA, van Engeland M, Weijenberg MP. Lifestyle, diet, and colorectal cancer risk according to (epi) genetic instability: current evidence and future directions of molecular pathological epidemiology. Current colorectal cancer reports. 2017;13(6):455-69.

28. Darmon N, Ferguson EL, Briend A. Impact of a cost constraint on nutritionally adequate food choices for French women: an analysis by linear programming. J Nutr Educ Behav. 2006;38(2):82-90.

29. Rajikan R, Zaidi NIA, Elias SM, Shahar S, Manaf ZA, Yusoff NAM. Construction of healthy and palatable diet for low socioeconomic female adults using linear programming. Int J Adv Sci Eng Inf Technol. 2017;7(1):125-31.

30. Franceschi S, Bidoli E, Negri E, Zambon P, Talamini R, Ruol A, Parpinel M, Levi F, Simonato L, La Vecchia C. Role of macronutrients, vitamins and minerals in the aetiology of squamous-cell carcinoma of the oesophagus. Int J Cancer. 2000;86(5):626-31.

31. Andriolo A. Diet and cancer. J Bras Patol Med Lab 2016; 52(6):366-366.

32. D'Elia L, Rossi G, Ippolito R, Cappuccio FP, Strazzullo P. Habitual salt intake and risk of gastric cancer: a meta-analysis of prospective studies. Clin Nutr. 2012;31(4):489-98.

33. Asmaa A, Zzaman W, Tajul A. Effect of superheated steam cooking on fat and fatty acid composition of chicken sausage. Int Food Res J. 2015;22(2): 598-605. 